\title{
Política económica y modo de acumulación en la Argentina de la posconvertibilidad
}

\section{Adrián Piva*}

Perfiles Latinoamericanos, 26(52) | 2018

DOI: $10.18504 / \mathrm{pl} 2652-006-2018$

Recibido: 2 de diciembre de 2015

Aceptado: 22 de marzo de 2017

\begin{abstract}
Resumen
En este artículo se muestra que un aspecto central del modo de acumulación y de sus tensiones durante la última década en Argentina fue el creciente desfase entre la política económica y las principales tendencias de la acumulación capitalista, lo cual se originó en que la dimensión específicamente política de la política económica condicionó la intervención del Estado. Dada la importancia de la caracterización del modelo económico argentino desde 2002 como neodesarrollista, se parte de precisar este concepto y se discute en qué medida la política económica del gobierno se le aproxima o aleja. Finalmente se expone el modo de acumulación en la Argentina de la posconvertibilidad, el lugar de la política económica y el significado del desfase señalado.
\end{abstract}

\begin{abstract}
In this article we show that a central aspect of accumulation mode and its tensions during the last decade in Argentina was a growing gap between economic policy and the main trends of capitalist accumulation in the period. This gap was originated in the way that the specifically political dimension of economic policy determined the course of State economic intervention. Given the importance attached to the characterization of the Argentine economic model since 2002 as neodevelopmentalist, we start from clarify the sense of neodevelopmentalist term for the major authors that used it and try to see to what extent the government's economic policy moves away of that concept. Then we advance in characterizing the mode of accumulation in the Argentina of post-convertibility and finally go back to the question of the place of economic policy and of the meaning of mentioned gap.
\end{abstract}

Palabras clave: Argentina, Estado, acumulación de capital, política económica, crisis económica, consenso, neodesarrollismo, posconvertivilidad.

Keywords: Argentina, State, capital accumulation, economic policy, economic crisis, consensus neodevelopmentalism, post-convertibility.

* Doctor en Ciencias Sociales por la Universidad Nacional de Quilmes (Argentina) | Profesor e investigador de la Universidad de Buenos Aires, la Universidad Nacional de Quilmes y CONICET, Argentina | adrianpiva@gmail.com 
l observar la evolución de la relación entre política económica y acumulación de capital durante el periodo posterior a la crisis del régimen de convertibilidad en Argentina, ${ }^{1}$ surgen dos evidencias. En primer lugar, los aspectos esenciales de la modalidad de acumulación que ya eran visibles en los primeros años del gobierno de Kirchner —iniciado en mayo de 2003-, se han mantenido con pocas variaciones y han mostrado las tensiones que lo atravesaban desde su inicio. En segundo lugar, fue notable la importancia que adquirió el principal aspecto transformado por la crisis de $2001^{2}$ y la posterior recomposición del poder de Estado: la dimensión específicamente política de la política económica, término que aquí se refiere al modo en que la reconstitución y reproducción de la dominación política — dimensión dominante del momento estatal de la reproducción capitalista- atraviesa la política económica. Esto no solo significa que la política económica no es meramente una técnica, sino que incorporar a su análisis en forma explícita la dimensión específicamente política afecta la manera en que debe pensarse su lugar en el modo de acumulación y las relaciones que mantiene con las demás variables que lo caracterizan: inserción en la economía mundial, evolución de la estructura productiva, comportamiento de la inversión y de la demanda, etcétera.

En los debates sobre el modo de acumulación en Argentina se suele abusar de la noción más o menos vulgar de modelo, utilizada para clasificar y periodizar destacando las continuidades o cambios en una política económica (Bonnet, 2007). Sin embargo, en términos más universales, y en particular en la tradición marxista, la noción de modo de acumulación está marcada por la escuela de la regulación. Y esta ha representado la relación entre la política económica y los demás aspectos del modo de acumulación como una relación de correspondencia. Determinados tipos de intervención estatal o de política monetaria corresponden a otros tantos de relación con el mercado mundial, funcionamiento del mercado laboral, orientación de la inversión, etc. La posibilidad de que en determinados países se produzcan por periodos más o menos

1 Entre abril de 1991 y enero de 2002, en Argentina estuvo vigente un régimen de convertibilidad monetaria que estableció un tipo de cambio fijo ( 1 peso $=1$ dólar). Esto implicó atar la política monetaria al resultado de la cuenta capital, ya que solo permitía la emisión de pesos contra el ingreso neto de divisas. A su vez, la fijación del tipo de cambio hizo de la evolución de la productividad una variable clave para la sostenibilidad del régimen cambiario.

2 Durante el año 2001 se desarrolló un proceso de movilización social que culminó en la rebelión popular del 19 y 20 de diciembre. La caída del presidente De la Rúa abrió un periodo de inestabilidad política que cerró con el ascenso al gobierno de Kirchner. El ciclo de conflicto social y de crisis política se dieron en estrecha relación con una profunda depresión económica iniciada en el cuarto trimestre de 1998 y que comenzó a superarse en el cuarto trimestre de 2002, fin de la convertibilidad mediante. 
prolongados relaciones de inadecuación o desfases entre la política económica y las direcciones más relevantes de la acumulación capitalista es subestimada como un desvío del "tipo ideal". Considerar seriamente la dimensión específicamente política de la política económica previene de tales simplificaciones y obliga a preguntarse por el lugar de esta última y a pensar en su singularidad para cada espacio y momento específico.

La discusión acerca del modo de acumulación en Argentina desde el fin de la convertibilidad y su definición de neodesarrollista ha estado atravesada por el problema descrito. En lo que sigue se mostrará que un aspecto central del desarrollo de la acumulación y de sus tensiones durante la década kirchnerista fue el creciente desfase entre la política económica y las principales tendencias de la acumulación capitalista, lo que fue resultado del modo en que la dimensión específicamente política de la política económica condicionó la intervención económica del Estado. ${ }^{3}$ Para esto primero se habrá de precisar el término neodesarrollismo de acuerdo a los autores que lo han acuñado y se confrontará en qué medida la política económica del gobierno se aproxima o aleja de dicho concepto. Luego se caracterizará el modo de acumulación en la Argentina de la posconvertibilidad para finalmente discutir el lugar de la política económica y el significado del desfase señalado.

\section{El "modelo económico" neodesarrollista}

El término neodesarrollismo fue acuñado por un conjunto de autores ligados al estructuralismo económico (Bresser, 2007; Ferrer, 2004; Frenkel, 2004). Con él se intentó señalar una estrategia de política económica —una estrategia nacional de desarrollo en términos de Bresser (2007) — que se orienta al desarrollo industrial en un contexto de mundialización productiva y financiera. Por lo tanto, el término neodesarrollismo refiere a un paquete de políticas económicas con objetivos definidos —o "modelo económico"— más que a un modo de acumulación. La diferenciación debe subrayarse porque en la mayoría de las discusiones, en especial entre los autores marxistas, ambas nociones se entremezclan. Hasta qué punto cambió o no el modo de acumulación respecto de los ańos noventa no debe confundirse con, ni reducirse a, los cambios en

3 Jessop $(1980,1990)$ apunta la posibilidad de esta falta de correspondencia entre estrategia de acumulación y proyecto hegemónico, aunque en términos algo diferentes del modo en que lo hacemos aquí. Esta idea también se articula con la contradicción entre acumulación y legitimación que identifica O’Connor (1981) y, desde otras perspectivas, Habermas (1995) y Offe (1992).

A. Piva | Política económica y modo de acumulación en la Argentina de la posconvertibilidad Perfiles Latinoamericanos, 26(52) | FLACso México | DoI: 10.18504/pl2652-006-2018 
la política económica — los cuales son evidentes—, aunque el análisis de esta es parte del estudio del modo de acumulación.

Los neodesarrollistas defendieron la implementación de políticas de tipo de cambio alto para impulsar la competitividad de la industria, una política fiscal que brindara un marco de sustentabilidad financiera a la acumulación (superávit fiscal) y una política monetaria que combinara metas de inflación con objetivos de empleo y actividad económica. Estas políticas pretendían fortalecer un proceso de industrialización dirigido a la exportación con mayores grados de integración nacional y/o regional de las cadenas de valor, capaz de asimilar las innovaciones tecnológicas desarrolladas en los países centrales e impulsar la innovación local. Admitían la intervención reguladora del Estado en los mercados de capitales y la intervención activa en el mercado cambiario, así como la introducción de políticas redistributivas para compensar las desigualdades del desarrollo hacia afuera y consolidar la demanda interna. Pero al mismo tiempo asimilaban la crítica neoliberal al Estado empresario.

Los neodesarrollistas articulan la caracterización y el balance de la reestructuración del capital y del Estado de los años noventa en América Latina con orientaciones y propuestas de política económica. Esto es, combinan análisis de procesos objetivos con análisis normativos o prescriptivos. Asimismo, muchas de esas propuestas se basan en las respuestas ensayadas por distintos gobiernos sudamericanos a las crisis de principios del siglo XXI. De conjunto, la vertiente principal del neodesarrollismo (Bresser, 2007; Frenkel, 2004; Frenkel \& Taylor, 2006) considera como fundamento de sus políticas gran parte de las reformas neoliberales, sobre todo en lo referente a la reforma del Estado y, con mayor incomodidad política, a la reorientación exportadora de una parte de la industria. ${ }^{4}$ En este último caso, la crítica al bajo valor agregado de las exportaciones y a la baja integración productiva nacional y regional se enlaza con el rechazo del regreso a las estrategias nacionales centradas y de industrialización orientadas al mercado interno. Asimismo, se encuentra ausente de su propuesta la protección arancelaria y los mecanismos de transferencias y subsidios a la industria. En este sentido, las retenciones a las exportaciones agropecuarias se hallan ligadas a la sustentabilidad fiscal, a la política de precios en un contexto de fuerte aumento de los precios de los alimentos a nivel mundial, a la inducción al procesamiento local de las materias primas y, en menor medida, a la redistribución de ingresos hacia sectores pauperizados de la población, pero no a mecanismos de transferencia a la industria propios del desarrollismo. La principal diferencia

4 A pesar de sus coincidencias, Aldo Ferrer ofrece una visión mucho más negativa del legado de las reformas neoliberales y con matices importantes en cuanto al papel de la demanda interna en el proceso de desarrollo (Ferrer, 2010). 
del neodesarrollismo respecto de las políticas neoliberales se encuentra en el rol que asignan al Estado en la estrategia de desarrollo. ${ }^{5}$ De acuerdo a los neodesarrollistas, el Estado debe intervenir con el fin de generar marcos que favorezcan la inversión productiva — sobre todo la industrial—, en un contexto de integración regional y mundial. Los instrumentos principales para esto serían la política cambiaria, la fijación de niveles de tasas de interés compatibles con la inversión productiva y que desincentiven los flujos especulativos de corto plazo $y$, en caso de ser necesario, las regulaciones de los flujos de capital. Ello se sigue del balance que realizan de las políticas de los ańos noventa: el tipo de cambio fijo y retrasado, las tasas de interés altas favorecidas por inconsistencias entre política fiscal (déficit) y monetaria y la apertura irrestricta del mercado de capitales, habrían dado predominio al sector financiero, lo que provocó burbujas especulativas, limitando al capital productivo —especialmente el industrialy destruyendo el tejido industrial interno. El cambio de políticas, entonces, debiera posibilitar un desarrollo industrial compatible con la evolución de la economía mundial desde mediados de los años setenta. La reorientación de los términos de intercambio favorable a las economías periféricas desde el bienio 2002-2003 constituiría una oportunidad para ensayar esas políticas y permitir así un salto en el desarrollo de las economías intermedias latinoamericanas. Este es el espacio de una limitada recuperación del viejo proyecto cepalino y de sus nociones de centro-periferia, aunque muy desdibujadas. Cuando explican los procesos de desarrollo, los enfoques neodesarrollistas privilegian el rol de los Estados periféricos y de las decisiones nacionales de política económica sobre la determinación de la inserción internacional y de las restricciones estructurales que nacen de la heterogeneidad interna (Katz, 2014).

Las políticas implementadas en Argentina, sobre todo entre 2002 y 2005 o tal vez 2007 (después volveremos sobre los cortes que representan ambos años), se inscriben en esta tendencia y han sido un referente para los neodesarrollistas, al punto que muchas de sus ideas se han originado en ellas. Al finalizar la convertibilidad, la devaluación llevó a un tipo de cambio alto y a un superávit comercial y fiscal. Los primeros años de la presidencia de Kirchner mantuvieron lo esencial de la política económica de Duhalde ${ }^{6}$ que había quedado a cargo del mismo ministro, Roberto Lavagna. Se sostuvo entonces el tipo de cambio alto

5 Nuevamente, Aldo Ferrer muestra un mayor distanciamiento de las reformas neoliberales y una visión más crítica de los planteos sobre la llamada globalización (Ferrer, 2010).

6 El entonces senador Eduardo Duhalde asumió la presidencia de la nación por decisión de la Asamblea Legislativa en enero de 2002. Su mandato debía concluir el 10 de diciembre de 2003, cuando expiraba el del expresidente De la Rúa. El asesinato de los militantes populares Maximiliano Kosteki y Darío Santillán a manos de fuerzas policiales el 26 de junio de 2002 creó un nuevo escenario de crisis política que forzó a Duhalde a adelantar las elecciones e impulsó el fin de su presidencia.

A. Piva | Política económica y modo de acumulación en la Argentina de la posconvertibilidad Perfiles Latinoamericanos, 26(52) | FLACso México | DoI: 10.18504/pl2652-006-2018 
con una intervención del Banco Central coordinada por el Ministerio de Economía, se limitó la expansión monetaria mediante políticas de esterilización a través de la emisión de bonos, se establecieron tasas de interés levemente negativas y se regularon limitadamente los flujos de capital de corto plazo imponiendo mínimos de permanencia. Las retenciones cumplieron un papel centralmente fiscal, lo que permitió financiar la expansión de programas sociales, en tanto que los subsidios a energía y transporte buscaron contener precios y tarifas más por razones de legitimidad que por el objetivo de subsidiar a la industria, aunque tuvieron también esa función. Después de 2005 las políticas monetaria y fiscal se alejaron progresivamente de las recomendaciones neodesarrollistas y se volvieron más expansivas. Más allá de 2007 se perdieron gradualmente los superávit gemelos y, frente a la crisis mundial, las políticas giraron hacia el sostenimiento de la actividad vía expansión de la demanda. A partir de 2011, el objetivo de estas políticas fue contener la crisis cambiaria en curso en medio de una creciente restricción externa, y evitar el ajuste o aplicándolo con un gradualismo no siempre compatible con los tiempos económicos.

Sin embargo, las transformaciones en la política económica dicen poco sobre los rasgos del modo de acumulación así como de su lugar en este. Se sobreestiman así las decisiones políticas de los gobiernos y se subestiman las continuidades profundas detrás de los cambios coyunturales. El apartado que sigue estudia las características de la acumulación, eso llevará a comprender qué significan esos cambios de política económica.

\section{El modo de acumulación de capital en la posconvertibilidad ${ }^{7}$}

Las principales tendencias de la acumulación capitalista en la posconvertibilidad se inscriben en un conjunto de transformaciones de largo plazo, algunas rastreables hasta la crisis de la industrialización por sustitución de importaciones (IsI) (1975/1976), pero surgidas en su mayor parte de la profunda reestructuración del capital y del Estado que se inició con la hiperinflación en $1989 .{ }^{8}$

7 La mayoría de los datos construidos y utilizados en esta y las siguientes secciones llegan hasta 2012, lo cual se debe a dos motivos. El primero es que gran parte de esta exposición es una comparación con la década de 1990. Para ello se usó la serie de cuentas nacionales a precios constantes de 1993, cuyo último dato es de 2012. Las cuentas nacionales base 2004, que arrojan datos hasta 2015, modificaron la metodología de medición resultando incomparables con el periodo previo al ańo base. En la última sección del artículo se uilizan dichos datos para describir el periodo 2012-2015. El segundo motivo es que la comparación entre periodos requirió, en los más de los casos, de restringirse a las fases expansivas (2003-2011, en la posconvertibilidad y 1991-1998, en la convertibilidad, y 1993-1998, para la serie disponible).

8 Al final del artículo se regresa a los problemas de periodización. 
Como hemos señalado en otros lugares (Piva, 2012), el rasgo dominante de ese proceso fue la reestructuración productiva y su corazón la reestructuración industrial. La apertura comercial y el tipo de cambio fijo supusieron la subordinación de la reproducción del capital local a la acción de la ley del valor a escala mundial y, con ello, la intensificación de la competencia. Tal intensificación indujo un proceso de reestructuración en la industria que resultó en la reducción absoluta y relativa de la producción industrial de mayor valor agregado y de la orientada al mercado interno, y en el aumento absoluto y relativo de las manufacturas de origen agropecuario (MOA) e industrial (MOI) destinadas a la exportación. De hecho, las MoI fueron las más dinámicas.

Sin embargo, la reestructuración también afectó al agro. Los noventa fueron años de importante tecnificación y de incorporación de las nuevas técnicas de siembra asociadas al uso de organismos genéticamente modificados, los transgénicos. Aunque algunas de las transformaciones productivas en el agro comenzaron en la primera mitad de los noventa, en la segunda, en un marco de deterioro de los términos de intercambio, la reestructuración en el agro fue particularmente intensa y abarcó el proceso de producción, la comercialización, la distribución geográfica de los diversos tipos de producción, las formas de propiedad, etc. La importancia que adquirió el sector agropecuario en la importación de bienes de capital es indicativa de tal suceso.

La reestructuración productiva, en particular la reorientación exportadora especializada en commodities de los capitales más concentrados de la industria, tuvo efectos profundos en la dinámica de la acumulación y en la composición de la burguesía. Repasemos sus consecuencias. En primer lugar, la reestructuración industrial significó la derrota de las fracciones mercadointernistas de la burguesía y la subordinación del capital menos concentrado a la estrategia de acumulación de la gran burguesía. En segundo, esa reestructuración fue el terreno de la internacionalización del capital local, que se desarrolló, por un lado, por medio de fusiones, adquisiciones y de la apertura de las empresas controladas por capitales de origen nacional a la participación extranjera y, por otro, por medio de la asimilación de los comportamientos —en términos de inversión, inserción productiva, endeudamiento, fuga, etcétera - del capital de origen nacional y extranjero. En tercer lugar, el papel de las finanzas como palanca de la reestructuración y acumulación capitalista modificó la relación entre capital productivo y financiero. Durante los noventa, la magnitud del monto de la inversión superó de continuo al ahorro interno, y la fuerte renovación de capital fijo - desarrollada sobre todo en la primera mitad de esa década - se apoyó en la apertura del mercado de capitales. De modo que el endeudamiento externo financió la inversión y la fuga de capitales. Al mismo tiempo, la persistencia de esta última significó que, al lado del fundamento productivo de la reproducción de la gran 
burguesía — sobre todo la industrial — de origen nacional, creció la acumulación de capital líquido por endeudamiento y fuga. Esta acumulación, subsidiaria de la primera, fungió como retaguardia financiera ante la fuerte inestabilidad de la acumulación productiva. ${ }^{9}$ La contraparte en el capital extranjero de este comportamiento - si bien sujeto a definiciones y cambios en las estrategias globales de acumulación de las transnacionales - es la remisión de utilidades. Esta articulación entre producción y finanzas y la estrategia financiera del capital productivo entrelazó capital productivo y financiero, sin suprimir las tensiones entre capital dinero y capital productivo propias de la reproducción capitalista. ${ }^{10}$ Por último, la reorientación exportadora de la gran burguesía industrial y la reestructuración del agro eliminaron la oposición gran burguesía agraria/gran burguesía industrial. Estas transformaciones explican la fuerte unidad de la burguesía en torno de los aspectos centrales de la estrategia de acumulación desarrollada en los noventa y respecto de las fuertes continuidades en la posconvertibilidad.

Estas líneas de continuidad —y que conducen a considerar la posconvertibilidad como subperiodo de la etapa que abre con la hiperinflación de 1989- se manifiestan en distintos indicadores. Primero, en la evolución de la composición de las exportaciones. Como se observa en la gráfica 1, las Mor fueron las que más crecieron en los periodos 1991-1998 y 2003-2012. Es decir, que en la fase de desarrollo de la acumulación se profundizó la reorientación exportadora de la industria y su peso en las exportaciones, procesos que se revierten durante la fase depresiva 1999-2002. Así, si se compara la contribución al total de las exportaciones industriales de las ramas manufactureras para 1998 y 2011, se observa que "Alimentos y bebidas" explica el 44\% de las exportaciones en 1998 y el 45.1\%, en 2011, y que las ramas cuyo aporte crece más son "Sustancias y productos químicos", "Metales comunes" y, aunque partiendo de un porcentaje muy bajo, "Equipos de transporte". Estas tres últimas ramas sumadas representaron en 2011 el $22.8 \%$ de las exportaciones manufactureras y en 1998 el 16.2\%. Si les incorporamos las exportaciones de vehículos, cuyo porcentaje en el total decreció levemente entre ambos años, explican casi el 40\% de las exportaciones manufactureras en 2011 (39.6\%) (INDEC, 2015).

9 Aquí se retoma a Astarita (2012), quien explica la reticencia inversora de la burguesía local y la fuga de capitales como respuesta a la inestabilidad en la acumulación de capital y en los marcos sociales de esta. En otro lugar he propuesto que dicha inestabilidad se fundamenta en las dificultades de la clase dominante para subordinar duraderamente el trabajo, en contraste con lo ocurrido en Brasil o Chile (Piva, 2013).

10 La discusión en este artículo con la tesis de Basualdo (2000) de una acumulación con centro en la "valorización financiera" refiere a la articulación entre acumulación productiva y financiera (mecanismo de endeudamiento y fuga) y no a la existencia de esta última. Aquí se sostiene que el centro de la acumulación de los ańos noventa fue el incremento de la producción y de la explotación, lo cual fue posible por la reestructuración productiva; y que la estrategia financiera se movió alrededor de ese centro. 


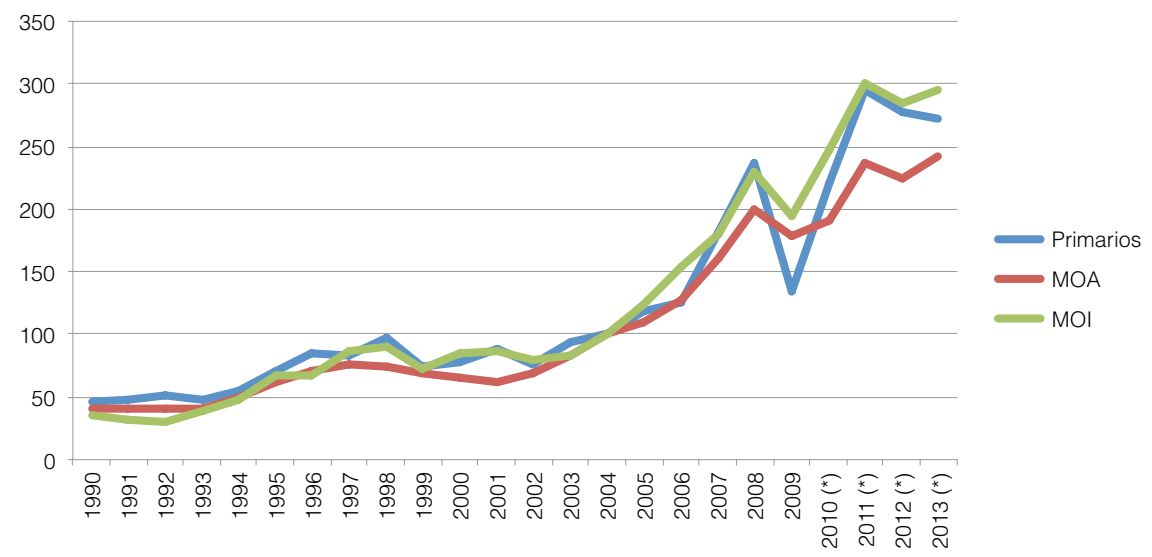

Fuente: Elaboración propia con información de INDEC (2015).

En segundo término, producto de la reorientación exportadora de la industria, la acumulación de capital se ha vuelto más dependiente de la demanda externa. Como se observa en los cuadros 1 y 2 , se acrecentó el peso de las exportaciones y decreció el del consumo total respecto del piB, ello a pesar de cierta reversión del fenómeno desde 2008. Mientras, a precios constantes (cuadro 1), el promedio de la relación exportaciones/PIB entre 1993 y 1998 fue del 9\%, entre 2003 y 2012 fue del 13\%. De modo correlativo, el promedio de la relación consumo total/PIB cayó de 81 a 77\%. El comportamiento opuesto desde 2008 no alcanzó para que las tasas regresaran a los niveles de 1998. En el caso del consumo la tendencia fue el aumento del público respecto del privado.

La reorientación exportadora del gran capital industrial no significó, sin embargo, que el resultado comercial del total de la industria dejara de ser deficitario. En ambos periodos esto último fue negativo y, si comparamos 2011 contra 1998, las únicas ramas superavitarias en ambos años fueron "Alimentos y bebidas" y "Productos del cuero". Mientras que en 2011 fue superavitaria la producción de "Metales comunes" y deficitaria la refinación de petróleo cuyo comportamiento había sido opuesto en los noventa (con base en cuentas internacionales del INDEC). Esto significa que desde el punto de vista sectorial el agro sigue siendo el proveedor neto de divisas y que la dependencia tecnológica de una industria productora de mercancías de bajo valor agregado da lugar a una cuenta comercial desequilibrada. Sin embargo, la clasificación por sectores encubre comportamientos de fondo significativos para comprender qué dirección tomó la acumulación capitalista desde 1989 y, en particular, durante la posconvertibilidad. 
Cuadro 1. Tasas de consumo total, público y privado; inversión bruta fija; y exportaciones sobre PIB a precios constantes (1993) (1993-2012)

\begin{tabular}{cccccc}
\hline Año & $\begin{array}{c}\text { Consumo privado/ } \\
\text { PIB }\end{array}$ & $\begin{array}{c}\text { Consumo público/ } \\
\text { PIB }\end{array}$ & $\begin{array}{c}\text { Consumo total/PIB } \\
\text { Inversión bruta } \\
\text { fija/PIB }\end{array}$ & Exportaciones/PIB \\
\hline 1993 & 69.20 & 13.51 & 82.72 & 19.06 & 6.91 \\
1994 & 69.36 & 12.82 & 82.18 & 20.47 & 7.53 \\
1995 & 68.26 & 13.30 & 81.56 & 18.31 & 9.49 \\
1996 & 68.27 & 12.87 & 81.14 & 18.89 & 9.68 \\
1997 & 68.81 & 12.29 & 81.11 & 20.56 & 10.05 \\
1998 & 68.57 & 12.23 & 80.80 & 21.09 & 10.70 \\
1999 & 69.55 & 12.99 & 82.55 & 19.08 & 10.94 \\
2000 & 69.64 & 13.17 & 82.81 & 17.92 & 11.32 \\
2001 & 68.67 & 13.50 & 82.17 & 15.81 & 12.17 \\
2002 & 66.00 & 14.38 & 80.38 & 11.28 & 14.08 \\
2003 & 65.60 & 13.40 & 79.00 & 14.32 & 13.71 \\
2004 & 65.88 & 12.63 & 78.51 & 17.65 & 13.60 \\
2005 & 65.73 & 12.27 & 78.00 & 19.84 & 14.14 \\
2006 & 65.31 & 11.91 & 77.21 & 21.61 & 13.99 \\
2007 & 65.49 & 11.79 & 77.28 & 22.60 & 14.04 \\
2008 & 65.36 & 11.80 & 77.17 & 23.09 & 13.31 \\
2009 & 65.10 & 12.55 & 77.65 & 20.56 & 12.35 \\
2010 & 65.00 & 12.58 & 77.58 & 22.84 & 12.97 \\
2011 & 66.07 & 12.81 & 78.88 & 24.45 & 12.42 \\
2012 & 67.71 & 13.39 & 81.10 & 22.83 & 11.38 \\
\hline
\end{tabular}

Fuente: Ministerio de Economía de la Nación (2015).

Cuadro 2. Tasas de consumo total, público y privado; inversión bruta fija; y exportaciones sobre PIB a precios corrientes (1993-2012)

\begin{tabular}{|c|c|c|c|c|c|}
\hline Аก̃o & $\begin{array}{c}\text { Consumo privado/ } \\
\text { PIB }\end{array}$ & $\begin{array}{c}\text { Consumo público/ } \\
\text { PIB }\end{array}$ & Consumo total/PIB & $\begin{array}{c}\text { Inversión Bruta } \\
\text { Fija/PIB }\end{array}$ & Exportaciones/PIB \\
\hline 1993 & 69.20 & 13.51 & 82.72 & 19.06 & 6.91 \\
\hline 1994 & 69.92 & 13.19 & 83.11 & 19.94 & 7.53 \\
\hline 1995 & 68.56 & 13.35 & 81.91 & 17.94 & 9.68 \\
\hline 1996 & 68.52 & 12.50 & 81.02 & 18.08 & 10.42 \\
\hline 1997 & 69.33 & 12.06 & 81.39 & 19.37 & 10.56 \\
\hline 1998 & 69.05 & 12.49 & 81.55 & 19.93 & 10.41 \\
\hline 1999 & 70.14 & 13.72 & 83.86 & 18.01 & 9.83 \\
\hline 2000 & 69.33 & 13.78 & 83.12 & 16.19 & 10.99 \\
\hline 2001 & 68.91 & 14.16 & 83.07 & 14.18 & 11.58 \\
\hline 2002 & 61.90 & 12.23 & 74.13 & 11.96 & 28.38 \\
\hline 2003 & 63.20 & 11.44 & 74.63 & 15.14 & 25.93 \\
\hline 2004 & 62.81 & 11.13 & 73.95 & 19.17 & 25.71 \\
\hline 2005 & 61.34 & 11.91 & 73.25 & 21.45 & 25.07 \\
\hline 2006 & 59.03 & 12.41 & 71.44 & 23.35 & 24.76 \\
\hline 2007 & 58.57 & 12.92 & 71.50 & 24.20 & 24.63 \\
\hline 2008 & 57.61 & 13.44 & 71.06 & 23.28 & 24.47 \\
\hline 2009 & 58.26 & 15.19 & 73.45 & 20.92 & 21.35 \\
\hline 2010 & 57.31 & 14.92 & 72.23 & 22.00 & 21.71 \\
\hline 2011 & 56.41 & 15.14 & 71.55 & 22.57 & 21.82 \\
\hline 2012 & 57.08 & 16.62 & 73.70 & 21.78 & 19.71 \\
\hline
\end{tabular}

Fuente: Ministerio de Economía de la Nación (2015). 
Primero, dentro del complejo oleaginoso, los sectores más dinámicos fueron los manufactureros (harinas, aceites y subproductos), que concentraron de 2003 a 2010 entre el 70 y el 80\% de las exportaciones totales del complejo, y no los granos sin procesar (Kejsefman, 2014). Segundo, ya en los años noventa las grandes empresas industriales mostraron superávits comerciales (Basualdo, 2000), mientras que el resto de la industria registraba déficit. Este comportamiento se agudizó durante la posconvertibilidad (Ortiz \& Schorr, 2009; Gaggero et al., 2014) señalando un rasgo central de la acumulación de capital desde 2002: la creciente dualización de la estructura económica y, particularmente, de la industrial entre un sector moderno con altos niveles de concentración y de productividad internacional y un sector atrasado de baja productividad.

Surge así la primera especificidad relevante de la posconvertibilidad: una limitada sustitución de importaciones industriales. Limitada en dos sentidos. 1) Porque su desarrollo no revirtió la reducción del peso de la industria en la economía, medido este en cuanto al valor bruto de producción total. Respecto del pIB total, en precios constantes o en precios corrientes, el peso del valor bruto de producción industrial en 2012 fue igual (en relación del valor de producción total a precios constantes) o inferior (en los demás casos) a 2003 y confirma la caída iniciada en 1993 (cuadro 3). 2) Porque la sustitución de importaciones se desarrolló, sobre todo en los primeros años, al amparo del tipo de cambio alto y articulada y subordinada a una estrategia de acumulación que fortaleció la reorientación exportadora del gran capital industrial. Por ello, la acumulación de la industria sustitutiva aprovechó los costos salariales bajos para impulsar una estrategia trabajo-intensiva, que incluyó la utilización del empleo precario. Por esta razón es de esperar que el resultado fuera una mayor heterogeneidad del sector industrial.

Cuadro 3. VAB de la industria manufacturera sobre VAB y PIB a precios de mercado (precios constantes de 1993)

\begin{tabular}{lllll}
\hline & 1993 & 1998 & 2003 & 2012 \\
\hline $\begin{array}{l}\text { VAB industria manufacturera/VAB a precios } \\
\text { de productor (precios constantes de 1993) }\end{array}$ & $19.81 \%$ & $18.78 \%$ & $17.49 \%$ & $17.49 \%$ \\
$\begin{array}{l}\text { VAB industria manufacturera/PBI precios de } \\
\text { mercado (precios constantes de 1993) }\end{array}$ & 18.24 & $17.19 \%$ & $16.39 \%$ & $15.94 \%$ \\
$\begin{array}{l}\text { VAB industria manufacturera /NAB a precios } \\
\text { de productor (precios corrientes 1993) }\end{array}$ & $19.81 \%$ & $19.37 \%$ & $24.04 \%$ & $19.67 \%$ \\
$\begin{array}{l}\text { Producción industrial/PBI precios de mercado } \\
\text { (precios corrientes 1993) }\end{array}$ & $18.24 \%$ & $17.84 \%$ & $22.49 \%$ & $17.74 \%$ \\
\hline
\end{tabular}

Fuente: Ministerio de Economía de la Nación (2015).

El desenvolvimiento de la productividad por ocupado en los capitales más concentrados de la industria y en el total de esta sirve de indicador del 
incremento de la dualización de su estructura. Para acercarse a esa medida se ha retomado la evolución de la relación entre el valor agregado bruto de producción (VAB) y el número de ocupados en las empresas industriales del panel de la encuesta nacional de grandes empresas (ENGE-INDEC) la cual reúne quinientos casos, y se comparó con el comportamiento del cociente entre el vaB industrial a precios corrientes (1993) (INDEC, 2015) y con dos mediciones del número de asalariados en la industria. Como se muestra en el cuadro 4, el vaB por ocupado de las empresas industriales de la ENGE-INDEC aumentó $221.4 \%$ entre 2003 y 2011 , dato que fue de $182 \%$ cuando se trata de toda la industria, esto si se toma como fuente del número de asalariados industriales la Encuesta de Indicadores Laborales del Ministerio de Trabajo de la Nación (EIL), y 205\%, si se retoma la Encuesta Industrial Mensual del INDEC (EIM). Es decir, con las limitaciones de comparar con fuentes distintas, en ambos casos los proxys de productividad por ocupado parecen mostrar un aumento mayor en las grandes empresas industriales que en el resto de la industria durante ese periodo, lo cual habría acrecentado la brecha entre sector moderno y atrasado. ${ }^{11}$

Cuadro 4. VAB de la industria manufacturera sobre ocupados industriales (ENGE-INDEC), VAB de la industria manufacturera sobre ocupados industriales (EIM), VAB de la industria manufacturera sobre ocupados industriales (EIL) (Variación porcentual 2003-2011)

\begin{tabular}{cccc}
\hline VAB/Ocupados (ENGE) & $\begin{array}{c}\text { VAB/Ocupados (EIM) Total } \\
\text { industria }\end{array}$ & $\begin{array}{c}\text { VAB/Ocupados (EIL) Total } \\
\text { industria }\end{array}$ \\
\hline $2003-2011$ & $221.4 \%$ & $205.7 \%$ & $182.8 \%$ \\
\hline
\end{tabular}

Fuente: INDEC (2015), Ministerio de Economía de la Nación (2015), Ministerio de Trabajo de la Nación (2015).

Junto a la profundización de la dualidad de la estructura económica se registró asimismo un salto en la concentración, centralización e internacionalización del capital local. Este fenómeno fue ampliamente estudiado, por lo que basta decir que todos los indicadores - porcentaje del vBP de las grandes empresas (ENGE-INDEC), participación en las exportaciones (ENGE-INDEC), peso de las ventas de la "cúpula industrial" en el PIB industrial (Manzanelli \& Schorr, 2013; Gaggero et al., 2014) — muestran que la concentración y centralización del capital industrial poscrisis de la convertibilidad crecieron y que, si bien con un decrecimiento posterior, se mantuvieron en niveles superiores a los de la convertibilidad durante todo el periodo. Lo mismo sucede con la internacio-

11 Los datos de Gaggero et al. (2014) muestran que esta dualización se verifica también al interior de la gran burguesía entre capitales de origen extranjero y los de origen nacional. Los primeros muestran una acumulación más intensiva y una más alta tasa de explotación con mejores salarios promedio, lo que se explica por su mayor productividad. 
nalización del capital local. Después de un fuerte aumento de la participación extranjera en las grandes empresas poscrisis de 2002 hay una ligera caída en los años posteriores, pero conservándose en niveles superiores a los de los noventa (Schorr, Manzanelli \& Basualdo, 2012; Gaggero et al., 2014; ENGE-INDEC, 2007; Boletín de prensa, Varios números, ENGE-INDEC).

En cuanto al destino de la inversión extranjera directa (IED), desde la segunda mitad de los noventa y con más intensidad durante la posconvertibilidad, se observó su crecimiento en las ramas de la minería y explotación de hidrocarburos, aunque la industria fue también uno de sus destinos importantes, tanto en términos totales como de aportes de capital. Alimentos y bebidas se han beneficiado de esa inversión, al igual que ramas industriales como productos químicos, plástico y vehículos automotores. De hecho, el industrial es el ámbito que más regularmente recibió este tipo de recursos. Entre 1992 y 2002 atrajo el 22\% del total de la IED, pero lo superaron el petróleo y la minería debido a que Repsol compró Yacimientos Petrolíferos Fiscales S. A. (YPF) (Giusani \& L'hopital, 2003). Durante la fase de la posconvertibilidad el sector industrial recuperó el segundo lugar tanto de aportes de capital como en cambios de manos, seguido del extractivo, apuntalado por las inversiones mineras (García, 2014). Es decir, que el capital extranjero participa activamente de la explotación de recursos naturales, con lógica extractiva, y en la expansión de la industria, en especial de la exportadora. Esto explica el auge de su participación en las exportaciones totales (Gaggero et al., 2014; García, 2014).

Ahora bien, el capital extranjero que ha incrementado su participación en los principales indicadores de la economía argentina está altamente internacionalizado en sus comportamientos, es decir, que su estrategia de acumulación es de escala mundial y sus cadenas de valor están crecientemente mundializadas. Por su parte, Gaggero et al. (2014) han detectado que los capitales de origen nacional que han permanecido dentro de lo que denominan "cúpula empresaria" 12 son los que han internacionalizado sus estrategias expandiendo sus negocios a otros países, intensificando su reorientación exportadora y manteniendo e incrementando el capital en estado líquido en el exterior.

El resultado conjunto de la reorientación exportadora y de la internacionalización de la gran burguesía, simultáneas con la ascendente concentración y centralización del capital, ha llevado a la internacionalización de la economía local. Ello, más el crecimiento desequilibrado provocado por la dependencia tecnológica y la dualización de la estructura de la economía han profundizado un desarrollo dependiente.

12 Que los autores definen como las doscientas empresas de mayor facturación anual en Argentina (Gaggero et al., 2014).

A. Piva | Política económica y modo de acumulación en la Argentina de la posconvertibilidad Perfiles Latinoamericanos, 26(52) | FLACso México | DoI: 10.18504/pl2652-006-2018 


\section{Acumulación de capital y relaciones sociales de fuerza}

La crisis y la recomposición de la acumulación en la Argentina de inicios del siglo XXI no pueden ser analizadas separándolas de la crisis y recomposición del poder político. Una y otra son momentos distintos de un mismo proceso de crisis y recomposición de la subordinación del trabajo al capital (Bonefeld, 1992; Jessop, 1990). Esto significa que al ocuparse de la acumulación siempre se debe tener presente la simultánea crisis y recomposición de la dominación política. Y que no puede analizarse el modo de acumulación sin referir las relaciones de fuerza que son la base y expresión de su desarrollo.

En 2001, el bloqueo popular de la vía deflacionaria de salida de la crisis hizo estallar junto con la convertibilidad las relaciones de fuerza que esta cristalizaba. ${ }^{13}$ Por lo tanto, la salida posconvertibilidad no podía limitarse a responder en términos inflacionarios al desafío popular, debía además recomponer la acumulación y la dominación con base en nuevas relaciones de fuerza. La recomposición del poder político requirió de la incorporación política y satisfacción gradual de las demandas populares. Pero entonces este hecho debió atravesar la construcción —no necesariamente la planeada— de la política económica.

Así es como cobra importancia un rasgo que diferencia la acumulación posconvertibilidad de aquella de los noventa, aunque en particular con la primera mitad de esa década: ${ }^{14}$ su carácter predominante de capital extensivo. Los cuadros 5 y 6 muestran que los aumentos de productividad horaria y por ocupado fueron superiores en los noventa a los de la posconvertibilidad, aunque las tasas de inversión, en términos corrientes o constantes, fueron inferiores a las de esos años (cuadros 1 y 2, páginas arriba). A su vez, el volumen físico de producción aumentó tres veces más entre 2003 y 2011 que entre 1991 y 1998. La contrapartida de estos datos fue el gran aumento del empleo y la caída del desempleo, un aspecto esencial de la reconstrucción del consenso político. La tasa de empleo se incrementó del $38.8 \%$, en el tercer trimestre de 2003 , al $43.4 \%$ en el tercer trimestre de 2011; mientras que la tasa de desempleo se redujo del $16.1 \%$, en el segundo trimestre de 2003, al 7.3\%, en el segundo trimestre de 2011. Esto en un contexto de sostenimiento (leve aumento) de la tasa de actividad que pasó del $46.3 \%$ al $46.7 \%$ en el mismo periodo (EPH-INDEC, 2015).

13 Al no haber aumentos sostenidos de productividad, el régimen de convertibilidad dejaba como alternativa para superar la crisis la caída nominal de los salarios y del gasto público. Para que la primera fuera exitosa debía ser mayor a la caída del resto de los precios, de modo que se tradujera en una recomposición de la tasa de ganancia empresaria. Esa salida fue "bloqueada" por la resistencia popular al ajuste (véase la nota 2).

14 La fase expansiva 1996-1998 también se apoyó en la renovación de capital fijo de la primera mitad. Ello explica los menores aumentos de productividad (Cfr. Piva, 2012) y la rápida caída del desempleo a nivel nacional desde el 17.3\% en octubre de 1996 al 12.4\% en 1998 (EPH-INDEC, 2015) 
Cuadro 5. Indicadores de la industria manufacturera: variación porcentual durante los periodos 1991-1998 y 2003-2011

\begin{tabular}{lcc}
\hline & Variación (\%) & Nivel general (\%) \\
\hline \multirow{2}{*}{ Volumen físico de producción } & $1991-1998$ & 31.7 \\
\hline \multirow{2}{*}{ Productividad horaria } & $2003-2011$ & 101.1 \\
\hline \multirow{2}{*}{ Productividad por obrero ocupado } & $1991-1998$ & 54.1 \\
& $2003-2011$ & 54.2 \\
\hline \multirow{2}{*}{ Productividad/Salarios IPC-INDEC/IPC 9 } & $1991-1998$ & 58.7 \\
\hline \multirow{2}{*}{ Productividad/Salarios IPIMM } & $2003-2011$ & 49.5 \\
\hline \multirow{2}{*}{ Intensidad laboral } & $1991-1998$ & 61.1 \\
& $2003-2011$ & -17.9 \\
\hline
\end{tabular}

Fuente: Ministerio de Industria de la Nación (2015), INDEC (2015), CIFRA (2015).

Cuadro 6. Productividad horaria y por ocupado de la industria manufacturera: variación anual promedio en los periodos 1991-1998 y 2003-2011

\begin{tabular}{lcc}
\hline & Var. anual promedio de la productividad horaria & $\begin{array}{c}\text { Var. anual promedio de la producti- } \\
\text { vidad por ocupado }\end{array}$ \\
\hline $1991-1998$ & $6.4 \%$ & $6.9 \%$ \\
$2003-2011$ & $5.6 \%$ & $5.2 \%$ \\
\hline
\end{tabular}

Fuente: Ministerio de Industria de la Nación (2015).

La caída del desempleo permitió la recuperación del poder reivindicativo de la clase obrera, lo que fue evidente en el crecimiento del salario real desde 2005 y para los asalariados registrados del sector privado (cuadro 7). La combinación de reducidos aumentos de productividad, disminución de horas trabajadas por obrero y la recuperación del salario real dieron lugar a la baja de la tasa de explotación en la industria, y muy probablemente en el conjunto de las actividades productivas. En el cuadro 5 (véase más arriba) se observa un indicador proxy de la tasa de explotación, el cociente de la productividad por ocupado y el costo salarial real por obrero en la industria (Gigliani \& Bercovich, 2006; Marticorena, 2013) para los periodos 1991-1998 y 2003-2011. El cuadro 5 muestra la evolución del indicador que surge de utilizar el índice de precios mayoristas de la manufactura (IPIMM) para deflactar la evolución salarial y también el que resulta de aplicar el IPC del INDEC para la década de los noventa y el IPC 9 provincias de CIFRA para la posconvertibilidad (CIFRA, 2012). ${ }^{15}$ El primero es el procedimiento

15 En 2007, el INDEC fue intervenido por el gobierno nacional. A partir de allí los datos de variación del índice de precios al consumidor presentaron inconsistencias internas y divergencias significa- 
adecuado para calcular el costo salarial real, pero resulta inservible para la posconvertibilidad dada la subestimación de los índices de precios calculados por el INDEC desde 2007. Mediante ese procedimiento, el proxy de tasa de explotación habría caído 44\%, entre 2003 y 2011, y aumentado 26.2\%, entre 1991 y 1998. El segundo procedimiento no permite calcular el costo salarial real en la industria aunque el resultado probablemente sea un mejor indicador para el periodo 2003-2011, ya que el IPC 9 provincias da una medida más confiable de la inflación minorista. Según este último indicador, el proxy de tasa de explotación habría caído 17.9\% entre 2003 y 2011, pero aumentado 66\% en los noventa, lo que — comparado con el 26.2\% utilizando el IPIMM - señala la posibilidad de diferencias significativas con el procedimiento adecuado. Considerando la evolución hasta 2007 (Marticorena, 2013), es muy probable que la reducción de la tasa de explotación no haya compensado su aumento en los noventa, como surge de deflactar los salarios por el IPC 9 provincias, lo que es consistente con otros datos.

Cuadro 7. Índices de salario real deflactados por IPC 9 provincias-CIFRA (2001-2014)

\begin{tabular}{lccc}
\hline Año & $\begin{array}{c}\text { Índice evolución salario real } \\
\text { general (Diciembre de cada } \\
\text { año. Diciembre 2001=100) }\end{array}$ & $\begin{array}{c}\text { Índice evolución salario real } \\
\text { sector privado registrado } \\
\text { (iciembre de cada año. } \\
\text { Diciembre 2001=100) }\end{array}$ & $\begin{array}{c}\text { Índice evolución salario real } \\
\text { sector privado no registrado } \\
\text { (Diciembre de cada año. } \\
\text { Diciembre 2001=100) }\end{array}$ \\
\hline 2001 & 100.00 & 100.00 & 100.00 \\
2002 & 76.29 & 82.88 & 67.19 \\
2003 & 82.53 & 92.74 & 71.62 \\
2004 & 85.03 & 97.02 & 75.50 \\
2005 & 91.08 & 108.79 & 75.70 \\
2006 & 98.77 & 118.52 & 83.29 \\
2007 & 96.70 & 113.56 & 82.29 \\
2008 & 96.23 & 109.47 & 92.24 \\
2009 & 97.72 & 111.73 & 97.41 \\
2010 & 97.93 & 114.54 & 95.29 \\
2011 & 103.41 & 126.87 & 103.06 \\
2012 & 104.01 & 127.88 & 111.24 \\
2013 & 100.96 & 123.44 & 109.55 \\
\hline
\end{tabular}

Fuente: INDEC, CIFRA.

tivas con los construidos por consultoras e institutos de investigación privados y de universidades nacionales. El Instituto CIFRA de la Central de Trabajadores Argentinos (CTA) construyó un nuevo índice de variación de precios a partir de datos producidos por institutos de estadísticas provinciales que mantuvieron la vieja metodología de medición. El índice conocido como "9 provincias" es de los más fiables por su alta correlación hasta 2006 con el IPC-INDEC y por la publicidad de la metodología de construcción. 
Por ejemplo, la distribución funcional del ingreso calculada por el Centro de Estudios de Población, Empleo y Desarrollo (CEPED) indica un aumento de la participación asalariada en el producto entre 2003 y 2011, pero que no compensa la pérdida originada en la hiperinflación y consolidada durante el ciclo de la convertibilidad (Sánchez, 2013). Salvia \& Vera (2013) muestran que la desigualdad medida con el coeficiente de Gini familiar habría caído hasta 2010 a niveles inferiores a los de la década de 1990, en coincidencia con lo evidenciado por otras mediciones (Maurizio \& Beccaria, 2012). Sin embargo, cuando excluyen del cálculo los ingresos no laborales de los hogares, la caída de la desigualdad entre 2003 y 2010 no traspasa los niveles promedio de la primera mitad de los noventa (Salvia \& Vera, 2013). Es decir, una hipótesis plausible es que una parte significativa de la caída de la desigualdad entre hogares desde 2008 se origina en las transferencias de ingresos, como la Asignación Universal por Hijo (AUH), y que sería mucho menor si se consideraran solo los aumentos de ingresos laborales.

Los datos expuestos parecen señalar que la caída del desempleo y el fortalecimiento de la posición negociadora de los trabajadores durante la posconvertibilidad posibilitaron una mejora de su situación —aumento del salario real, menor tasa de explotación, mayor participación en el producto, caída de la desigualdad, según distintas medidas-, pero que no revirtió los resultados de la fuerte ofensiva contra la clase obrera que se dio durante la hiperinflación y la primera mitad de los noventa. A pesar de ello, dicha mejora implica que la acumulación se desarrolló sobre la base de una relación de fuerzas más favorable para el trabajo que en la década de 1990. Pero esta relación de fuerzas solo se abrió camino a través de la acción del Estado y es aquí donde el análisis de la dimensión específicamente política de la política económica y su relación con las tendencias de la acumulación capitalista cobran importancia.

El interregno duhaldista y los primeros dos años de gobierno kirchnerista muestran continuidades esenciales en la política económica y, como se planteaba más arriba, un paquete de medidas e instrumentos que permiten calificarla de neodesarrollista. El crecimiento fue impulsado por la recuperación de la tasa de ganancia, producto de la devaluación con caída del salario real, y de la mejora de los términos de intercambio, debida al boom de los commodities. Durante esta fase la intervención estatal buscó sostener un tipo de cambio alto y tasas de interés levemente negativas en un contexto de inflación moderada y superávit comercial y fiscal. La implementación del Plan Jefes y Jefas de Hogar Desocupados durante el gobierno de Duhalde y el retorno a políticas sociales más focalizadas durante los primeros años de la presidencia de Kirchner buscaron contener el impacto sociopolítico del aumento de la desigualdad y de la pobreza derivados de la crisis. La asistencia social, el aumento del empleo y la 
recuperación del consumo de los sectores medios permitieron articular el relanzamiento de la acumulación con la reconstrucción de la legitimidad política. Sin embargo, la presión y recuperación salarial empezaron a sentirse recién en 2005 , junto con un fuerte aumento del conflicto sindical y el peso del consumo interno decreció en relación al de las exportaciones. La política económica se articuló con - y sostuvo a - un proceso de acumulación promovido por la exportación de productos industriales de bajo valor agregado y basado en bajos costos salariales relativos, alrededor del cual se desarrolló la limitada sustitución de importaciones ya referida.

Las tensiones entre política económica y acumulación de capital comenzaron a manifestarse en 2005 y, desde esta perspectiva, la salida del ministro de Economía, Roberto Lavagna, constituyó un acontecimiento significativo. La disputa entre el Ministerio de Economía y los Ministerios de Planificación y de Trabajo que derivaron, finalmente, en la renuncia de Lavagna tuvieron como eje la política fiscal y salarial. La posición de Lavagna iba en el sentido de moderar la expansión del gasto público y contener los aumentos salariales. Este último punto en particular resultaba sensible en el marco del retorno de las paritarias desde 2004 y de aumento del conflicto obrero a niveles no vistos desde fines de los años ochenta. La salida de Lavagna era sintomática del punto en que la lógica de reconstrucción y reproducción del consenso político vía la satisfacción gradual de demandas populares entró parcialmente en conflicto con la estrategia de acumulación alimentada por las exportaciones y una industrialización limitada soportada por bajos costos salariales. Veamos solo algunos aspectos significativos de lo que se puede caracterizar como un desfase entre política económica y acumulación capitalista que se explica en la dimensión específicamente política de la política económica, es decir, en su inscripción en una estrategia general de reconstrucción y reproducción del poder político.

Si bien durante los años siguientes a la salida de Lavagna las negociaciones salariales siguieron pautas informales que ponían techos a los aumentos, los incrementos salariales siguieron un sendero que dislocaba los objetivos de la política económica. De este modo, aumentos salariales superiores a los incrementos de productividad y del movimiento del tipo de cambio movieron el tipo de cambio meta para sostener los niveles de competitividad. Pero también la política monetaria se hizo más expansiva por dos motivos centrales: por una mayor intervención cambiaria debida al aumento del tipo de cambio meta en condiciones de superávit comercial y con esterilización parcial de la nueva emisión, y por la política de convalidación monetaria del traslado a precios de los aumentos salariales.

Los subsidios al transporte, la energía y demás tarifas de servicios públicos surgieron como un compromiso para evitar aumentos de tarifas en un esce- 
nario de posdevaluación de alto grado de conflictividad social y en un marco de conservación del esquema de privatizaciones. Pero conforme el aumento de las tarifas entraba en conflicto con la construcción y conservación del consenso político se prolongó en el tiempo y sus dimensiones crecieron junto con la aceleración de la inflación. Desde 2008 empezó a ser un problema fiscal serio y particularmente desde 2010 fue un elemento central en la reaparición del déficit fiscal. Por este medio se transformó además en una variable que explica una parte significativa del aumento de la emisión monetaria para cubrir un déficit creciente.

La política monetaria expansiva se transformó en un problema debido a que se desarrolló en condiciones de restricciones de la oferta y de debilidad de la moneda nacional para funcionar como reserva de valor. Del lado monetario porque la moneda nacional funciona débilmente como dinero a causa de las reiteradas crisis de este desde 1975. Eso explica que aun en contextos de relativa fortaleza económica y financiera, como la de la Argentina en 2005 y 2006, la flexibilidad para emitir dinero sin consecuencias inflacionarias sea mucho más restringida que incluso en otros países dependientes. En 2006, de hecho se muestra una caída de la demanda de dinero cuando los niveles de inflación eran todavía de un dígito y las tasas de interés real eran levemente negativas. Del lado de la oferta, la "reticencia inversora" funcionó como un límite para respuestas más vigorosas de la oferta a la expansión de la demanda. Siguiendo a Astarita (2013), la fuga de capitales y la remisión de utilidades de empresas extranjeras funciona como un reaseguro frente a una historia reciente de inestabilidad. En estas condiciones la expansión monetaria dio lugar a un proceso inflacionario que impactó negativamente en la política de tipo de cambio alto, en las cuentas fiscales y fue parte de la explicación de la reaparición de tensiones cambiarias.

Sin embargo, el desfase entre política económica y acumulación de capital se desarrolló plenamente más allá de 2007. En este sentido, el conflicto de 2008 con la burguesía agraria y el cambio del contexto internacional significan un nuevo giro en esa relación.

Ya se mencionó que después de 2008 se observa una reversión parcial de algunas de las tendencias presentes desde los años noventa y profundizadas desde 2002. Una de ellas (véanse los cuadros 1 y 2 más arriba) es un leve crecimiento del porcentaje del consumo total en el PIB y una correlativa pérdida de peso de las exportaciones, aunque sin volver a los niveles de los noventa. Pero también es visible el aumento del peso del consumo público respecto del privado. Mientras que hasta 2007 el privado crece más que el público, desde 2008 ocurre lo inverso, con la excepción de 2011 —año de fuerte recuperación del salario real- en el que crecen a la par (aunque vuelve a ser levemente superior 
el aumento del consumo público). Asimismo se observa, en contraste con los años noventa, que desde 2008 el consumo público cumple una función contracíclica. Una evolución que se desarrolla simultáneamente con la reaparición del déficit fiscal y, desde 2011, de la restricción externa. Es de destacar que el gobierno ha intentado reducir subsidios y limitar los aumentos salariales con poco éxito, es decir, debiendo retroceder ante el rechazo masivo, hasta 2013 y 2014, años en los que se realiza un ajuste salarial gradual (cuadro 7) y una reducida quita de subsidios en medio de una recesión y crecientes dificultades en el sector externo.

Resumiendo, desde 2002 se observa la profundización de una estrategia de acumulación impulsada por la exportación de productos agrarios e industriales de poco valor agregado y una limitada sustitución de importaciones, basados ambos en bajos costos salariales. Sin embargo, después de 2005 y, centralmente, desde 2008 se evidencia un desfase entre política económica y acumulación de capital que debe ser considerado cuando se caracteriza la dinámica de acumulación en la posconvertibilidad. Un desfase que expresa una alteración en la relación de fuerzas favorable a los trabajadores sobre la base de la cual debió reconstruirse - después de su crisis-y reproducirse el poder político. Esta dimensión constitutiva del Estado, la de la reconstitución y reproducción de la dominación política, sobredetermina la política económica e imposibilita la correspondencia "típico-ideal" entre política económica y necesidades de la acumulación capitalista.

\section{La dualización estructural como límite de la intervención específicamente política del Estado durante la posconvertibilidad}

Con la evidencia de diversos trabajos, ya fue señalado arriba que la caída de la desigualdad y la reducción de la pobreza a niveles inferiores a los de la primera mitad de los noventa se explica por los ingresos no laborales, es decir, por las transferencias y programas sociales del Estado. Y que todos los indicadores laborales muestran mejoras significativas: reducción de la tasa de explotación, aumento del salario real y de la participación en el producto, etc., aunque sin traspasar el piso de la primera mitad de la década de 1990. Entre esos indicadores se encuentra también el trabajo en negro que cayó del $51.1 \%$, en el segundo trimestre de 2003, al 33.5\%, en el último trimestre de 2013 (INDEC, 2015). Sin embargo, el trabajo en negro en 2013 no distaba mucho del promedio de los años noventa. El porcentaje de trabajo asalariado en negro para el Gran Buenos Aires en el cuarto trimestre de 2013 fue 37.1\% (INDEC, 2015), mientras que en 1998 era de 36.7\% (INDEC, 2015). Si bien los datos no son del 
todo comparables por los cambios introducidos en la EPH en 2003, sirven para indicar que los porcentajes se encuentran en niveles más o menos similares. La pregunta que surge es si la interrupción del crecimiento económico impidió la continuidad de un proceso de mejoras de los indicadores sociolaborales con el que se revertían los resultados de la reestructuración capitalista de los años noventa o si las mejoras encontraron un núcleo duro ligado a las características del proceso de acumulación. No es posible responder taxativamente a esta cuestión, pero sí lo es exponer hipótesis sobre la relación entre el desempeño de varios de esos indicadores y algunas características del modo de acumulación de capital, en particular la profundización de la dualidad estructural.

Salvia \& Vera (2013) analizan la contribución de los hogares de los diferentes tipos de ingresos laborales a la desigualdad. Ellos indican que, entre 2003 y 2010, aun en un contexto de caída de la desigualdad de los hogares, el pasaje de ocupados en puestos "menos informales" a puestos formales del sector moderno puede leerse como un retorno a la estructura ocupacional precrisis y no como un cambio cualitativo. También concluyen que el aumento del número de empleados en el sector formal no impidió que se profundizara el empobrecimiento relativo de los hogares con asalariados y no asalariados insertos en el informal y la polarización socioocupacional entre ambos sectores.

Algo similar cabe decir de la evolución del empleo en negro. Si bien cae significativamente, lo hace para regresar a niveles precrisis, un comportamiento compatible con el modo de acumulación descrito más arriba. En primer término, el aumento de la actividad y del empleo tuvo un fuerte impulso en la construcción, ramo que históricamente tuvo altos niveles de empleo en negro. De igual forma, la limitada sustitución de importaciones que se dio al abrigo de la devaluación y de los bajos costos laborales poscrisis recurrió al empleo en negro, lo cual se registra en la industria textil aunque no se limita a esta. A esto hay que agregar la persistencia de un amplio sector informal que encubre una población sobrante que el sector moderno no puede absorber, la caída de la elasticidad empleo-producto desde 2007 y el relativo estancamiento o débil descenso del desempleo una vez alcanzado un piso superior al 7\%, más elevado que el de la década de los ochenta.

Es decir, la evolución de la desigualdad de los hogares de acuerdo a sus ingresos laborales y del empleo en negro, y los límites que encontró su reducción desde 2007, parecen ser un reflejo de la reproducción de la dualidad de la estructura económica entre un sector moderno y otro atrasado que caracteriza la acumulación de capital desde los noventa. Desde este punto de vista, la dimensión específicamente política de la intervención del Estado que quiso recomponer y reproducir la dominación política con la incorporación política y satisfacción gradual de las demandas populares encuentra en la dinámica de 
la acumulación un tope; más allá de este, el desfase entre política económica y acumulación solo conduce a niveles crecientes de desequilibrio y contradicciones macroeconómicas. La "sana" política neodesarrollista no sería más que una política económica adecuada para el desarrollo de una sociedad dual con una política redistributiva basada en transferencias de ingresos a los sectores precarizados y empobrecidos.

\section{Dependencia y restricción externa como límites a la "autonomía" del Estado}

Otro elemento propio de la acumulación de capital durante la posconvertibilidad, en relación con los ańos noventa, fue la "latente" dependencia financiera. En la convertibilidad la reestructuración productiva y los fuertes déficit de cuenta corriente se financiaron con endeudamiento, es decir, que la acumulación productiva requería de financiamiento externo. En la posconvertibilidad, la reversión de la tendencia secular hacia el deterioro de los términos de intercambio fue la base de importantes saldos comerciales y de cuenta corriente. En esas condiciones, la virtual exclusión de los mercados internacionales de crédito, nunca del todo superada a pesar de la reestructuración de la deuda externa entre 2002 y 2005, pasó inadvertida y además los Estados de la región, entre ellos el argentino, ganaron capacidad de arbitraje entre fracciones del capital y de intervención redistributiva entre capital y trabajo.

Sin embargo, aquí se habla de "latencia" de la dependencia financiera porque el crecimiento desequilibrado de la industria y la tendencia hacia el deterioro del balance cambiario - entre otros factores por la fuga de capitales y la remisión de utilidades_ - permanecieron; y a esto se sumó el déficit energético y el pago de intereses y capital de la deuda externa, aun en un contexto en el que el peso de esta en el PIB se reducía. Es decir, la restricción externa al crecimiento propia de una estructura dual, atrasada y dependiente aparece como un borde infranqueable al desarrollo de la acumulación y a la aparente autonomía de la política económica respecto del capital. Llegados a este punto, en nuestro caso, a partir de 2011 lo que se pone en cuestión es la posibilidad misma del desfase entre política económica y acumulación de capital. Ello se puso de manifiesto en el periodo de cuasi estancamiento que se abrió en 2012. La tasa promedio de crecimiento del PIB entre 2012 y 2015 fue de $0.37 \% .{ }^{16}$ Pero al tiempo que el consumo privado se estancaba y la inversión caía, crecía el consumo público

16 Promedio de variación anual del PIB a precios constantes de 2004 (INDEC. Recuperado de www.indec.gob.ar). 
(cuadro 8). Es decir, la conservación de una situación de cuasi estancamiento dependió cada vez más estrechamente de una intervención contracíclica del Estado que era crecientemente insostenible en un marco de restricción externa y déficit fiscal en aumento. Como contrapartida, el salario real general y el del sector privado registrado experimentaban un comportamiento a la baja (cuadro 7 , páginas arriba).

Cuadro 8. Tasas de consumo total, público y privado e inversión bruta fija sobre el PIB a precios constantes de 2004, (2004-2015)

\begin{tabular}{lcccc}
\hline Año & Consumo privado/PIB & Consumo público/PIB & Consumo total/PIB & Inversión bruta fija/PIB \\
\hline 2004 & 64.3 & 11.1 & 75.4 & 15.9 \\
2005 & 63.5 & 11.2 & 74.7 & 16.9 \\
2006 & 65.2 & 10.8 & 76 & 17.9 \\
2007 & 65.4 & 10.7 & 76.1 & 19.8 \\
2008 & 67.4 & 10.7 & 78.1 & 20.7 \\
2009 & 67.8 & 12.1 & 79.9 & 17.0 \\
2010 & 68.4 & 11.6 & 80 & 19.5 \\
2011 & 70.6 & 11.4 & 82 & 21.6 \\
2012 & 72.1 & 11.9 & 84 & 20.3 \\
2013 & 73.0 & 12.2 & 85.2 & 20.3 \\
2014 & 71.6 & 12.9 & 84.5 & 19.4 \\
2015 & 72.4 & 13.4 & 85.8 & 19.7 \\
\hline
\end{tabular}

Fuente: INDEC (2016).

De este modo, la crisis de la acumulación capitalista tendía a disolver el fundamento mismo de la intervención estatal "autónoma” y el déficit fiscal y externo presionaban por un ajuste que parecía cada vez más urgente según el Estado perdía capacidades institucionales.

\section{Conclusiones}

Desde 1989, en consonancia con la expansión capitalista caracterizada por la mundialización de las relaciones capitalistas (Astarita, 2004), se ha venido desarrollando y profundizando una estrategia de acumulación impulsada por la exportación de productos industriales de bajo valor agregado. Resultado de una reestructuración productiva basada en una enorme derrota de la clase obrera, dicha modalidad de acumulación produjo y agudizó la dualidad estructural entre un sector moderno y otro atrasado en la industria y en el conjunto de la economía, al mismo tiempo que se desplegaron la concentración, la centralización y la internacionalización del capital local. 
En todo esto es posible advertir dos fases cuyo quiebre fue la rebelión popular de 2001: i) la fundacional — que podemos denominar neoliberal-, caracterizada por políticas de apertura y tipo de cambio fijo que intensificaron la competencia, con lo que indujeron un vigoroso proceso de reestructuración productiva; y ii) la neodesarrollista/neopopulista. ${ }^{17} \mathrm{La}$ dinámica de acumulación en este subperiodo se caracterizó por: a) ser fundamentalmente de capital extensiva — basada en la renovación de capital fijo de la primera mitad de los noventa-; $b$ ) una limitada sustitución de importaciones — posible por el paraguas cambiario, los bajos costos laborales y estar articulada y subordinada a la orientación exportadora de la gran burguesía industrial—, y c) la "latencia" de la dependencia financiera. Este último rasgo tuvo su fundamento en la reversión del deterioro de los términos de intercambio que posibilitó superávits de cuenta corriente y, con ellos, mayores capacidades de arbitraje del Estado entre clases y fracciones de clases. Justamente el punto enfatizado en este trabajo.

La posconvertibilidad se caracteriza por un desfase entre política económica y acumulación capitalista que expresa una alteración de la relación de fuerzas favorable a los trabajadores sobre la base de la cual debió reconstruirse — después de su crisis- y reproducirse el poder político. Esta dimensión constitutiva del Estado sobredeterminó la política económica e imposibilitó la correspondencia "típico-ideal" entre política económica y necesidades de la acumulación capitalista. No obstante, esa intervención encontró un límite en la dinámica dualizadora de la acumulación de capital que impone un piso a la reducción de la pobreza, la desigualdad, el desempleo y el empleo precario. Más allá de esa frontera, el desfase entre política económica y acumulación solo conduce a niveles crecientes de desequilibrio y de contradicciones macroeconómicas. La restricción externa al crecimiento propia de una estructura dual, atrasada y dependiente aparece, entonces, como un límite último e infranqueable del desarrollo de la acumulación y de la aparente autonomía del Estado respecto del capital. Llegados a este punto lo que se pone en cuestión es la posibilidad misma de ese desfase.

\section{Referencias}

Astarita, R. (2012). Inversión y la "estructura social de la acumulación. Recuperado el 10 de septiembre de 2015, de http://rolandoastarita.wordpress.com/

Astarita, R. (2013). Debate sobre la inflación en Argentina. Partes I a IV. Recuperado de http:// rolandoastarita.wordpress.com/

17 Para una conceptualización del "neopopulismo" véase Piva (2013b). 
Astarita, R. (2004). Valor, mercado mundial y globalización. Buenos Aires: Ediciones Cooperativas.

Basualdo, E. (2000). Concentración y centralización del capital en la Argentina durante la década del '90. Buenos Aires: Universidad Nacional de Quilmes.

Bonefeld, W. (1992). La reformulación de la teoría del Estado. En Hirsch, J. et al., Los estudios sobre el Estado y la reestructuración capitalista (pp. 51-96). Buenos Aires: Tierra del Fuego.

Bonnet, A. (2007). Argentina: ¿̨un nuevo modelo de acumulación? Anuario EDI, (3), 51-67.

Bresser Pereyra, L. C. (2007). Estado y Mercado en el nuevo desarrollismo. Nueva Sociedad, (210), 110-125.

CIFRA (2012). Propuesta de un indicador alternativo de inflación. Recuperado el 10 de septiembre de 2015, de http://www.centrocifra.org.ar/docs/CIFRA\%20-\%20IPC-9\%20(Marzo\%20 2012).pdf

Ferrer, A. (2010). Raúl Prebisch y el dilema del desarrollo en el mundo global. Revista CEPAL, (101), 7-15.

Ferrer, A. (2004). Globalización, desarrollo y densidad nacional. Pesquisa \& Debate, (226), 200-208.

Frenkel, R. (2004). Real Exchange Rate and Employment in Argentina, Brazil, Chile and Mexico. Documento preparado por el G24, Washington, D. C.

Frenkel, R. \& Taylor, L. (2006). Real Exchange Rate, Monetary Policy and Employment. DESA working paper $\mathrm{n}^{\circ} 19$. Nueva York: United Nations.

Gaggero, A. et al. (2014). Restricción eterna: el poder económico durante el kirchnerismo. Buenos Aires: Futuro Anterior.

García, G. D. (2014). Inversión extranjera directa y empresas extranjeras: rupturas y continuidades en Argentina, 1990-2012. Actas de las VII Jornadas de Economía Crítica. La Plata: Sociedad de Economía Crítica de la República Argentina.

Gigliani, G. \& Bercovich, A. (2006). Productividad y salarios industriales en la "era Kirchner". Anuario EDI, (2), 86-101.

Giussani, L. A. \& L'hopital, M. F. (2003). La inversión extranjera directa en Argentina (19922002). Buenos Aires: Dirección Nacional de Cuentas Internacionales/INDEC.

Jessop, B. (1990). State theory: Putting the capitalist State in its place. Cambridge: Polity Press. 
Katz, C. (2014). ¿Qué es el neo-desarrollismo? I-Una visión crítica. Economía. Recuperado el 10 de septiembre de 2015, de http://katz.lahaine.org/?p=232

Kejsefman, I. (2014). Neodesarrollismo: ¿Qué hay de neo y qué de desarrollista en la Argentina de la postconvertibilidad?. Actas de las VII Jornadas de Economía Crítica. La Plata: Sociedad de Economía Crítica de la República Argentina.

Manzanelli, P. \& Schorr, M. (2013). Oligopolio e inflación. Aproximación al proceso de formación de precios en la industria argentina en la posconvertibilidad. Realidad Económica, (273), 25-52.

Marticorena, C. (2013). Relaciones laborales y condiciones de trabajo en la industria manufacturera durante la postconvertibilidad. En Grigera, J. (Comp.). Argentina después de la convertibilidad (2002-2011) (pp. 135-162). Buenos Aires: Imago Mundi.

Maurizio, R. \& Beccaria, L. (2012). Reversiones y continuidades bajo dos regímenes macroeconómicos diferentes. Mercado de trabajo e ingresos en Argentina 1990-2010. Desarrollo Económico, (52), 205-228.

Ortiz, R. \& Schorr, M. (2009). Crisis internacional y alternativas de reindustrialización en Argentina. Documento de Investigación Social núm. 7. Buenos Aires: UNSAM.

Piva, A. (2012). Acumulación y hegemonía en la Argentina menemista. Buenos Aires: Biblos.

Piva, A (2013). 30 años de democracia en la Argentina (1983-2013). Actas III Jornadas de la Revista Conflicto Social. Buenos Aires: Instituto de Investigaciones Gino Germani/Facultad de Ciencias Sociales, Universidad de Buenos Aires.

Piva, A (2013b). ¿Cuánto hay de nuevo y cuánto de populismo en el neopopulismo? Kirchnerismo y peronismo en la Argentina post 2001. Trabajo y Sociedad, (21), 135-157.

Salvia, A. \& Vera, J. (2013). Heterogeneidad estructural y distribución de los ingresos familiares en el Gran Buenos Aires (1992-2010). Desarrollo Económico, (208), 427-462.

Sánchez, M. A. (2013). La distribución funcional del ingreso hacia el interior del universo asalariado argentino (1997-2011). Actas de las VII Jornadas de Economía Crítica. La Plata: Sociedad de Economía Crítica de la República Argentina.

Schorr, M., Manzanelli, P. \& Basualdo, E. (2012). Elite empresaria y régimen económico en la Argentina. Las grandes firmas en la posconvertibilidad. Documento de Trabajo núm. 22. Buenos Aires: Flacso Argentina. 